\title{
Особенности сорбционного извлечения метаналя волокнистым ионообменником ФИБАН A-5W
}

\author{
Васильева Е.В., Воронюк И.В., Елисеева Т.В. \\ ФГБОУ ВО «Воронежский государственньій университет», Воронеж
}

Поступила в редакцию 15.03.2019 г.

DOI: https://doi.org/10.17308/sorpchrom.2019.19/740

Определены кинетические и равновесные характеристики сорбции метаналя волокнистым ионообменником ФИБАН A-5W, имеющим в структуре вторичные и третичные аминогруппы, в статических условиях. Установлено время достижения равновесия в системе раствор метаналя - сорбент. На основе подхода Бойда-Адамсона проведен анализ кинетических кривых сорбции, осуществлена оценка лимитирующей стадии процесса поглощения альдегида. Получены изотермы сорбции метаналя при разных температурах и проведена их интерпретация с привлечением ряда известных моделей. Рассчитаны значения свободной энергии Гиббса процесса поглощения с использованием константы сорбционного равновесия уравнения Ленгмюра.

Ключевые слова: волокнистый ионообменник, метаналь, изотерма сорбции, кинетика поглощения, лимитирующая стадия сорбции.

\section{The features of methanal sorption by the fibrous ion-exchange resin FIBAN A-5W}

\author{
Vasileva E.V., Voronyuk I.V., Eliseeva T.V. \\ Voronezh State University, Voronezh
}

\begin{abstract}
Aliphatic carbonyl compounds, in particular methanal, make significant contribution to environmental pollution. Removal of this compound from various kinds of water is an important eco-chemical task. The granular anion-exchange resins are known as effective sorbents of aliphatic aldehydes. This study considers the equilibrium and kinetic characteristics of methanal sorption by the ion-exchange fibers containing secondary amino groups in the free base form.

The ion-exchange fiber FIBAN A-5W is used as a sorbent. It has secondary and tertiary amino groups in the structure. The kinetic curves of methanal sorption have been obtained under static conditions in the thermostatic shaker using the limited volume procedure. The concentration of the initial solution is $0.0060 \mathrm{~mol} / \mathrm{dm}^{3}$. Sorption isotherms have been measured by varying concentration procedure at temperature values of $298 \pm 2 \mathrm{~K}$ and $323 \pm 2 \mathrm{~K}$.

The required time to reach equilibrium in the sorbate-sorbent system at a temperature of $298 \mathrm{~K}$ and $323 \mathrm{~K}$ is 240 minutes and 180 minutes, respectively. The decrease of time to reach equilibrium indicates on a change in the sorption mechanism of methanal when the temperature increases. The application of the BoydAdamson formal approach to the kinetic curves has revealed the limiting stage of methanal sorption at different temperatures. The study of the methanal uptake by the fibrous ion-exchange resin has shown that when the temperature increases, the capacity of the sorbent also increases from $4.90 \mathrm{mmol} / \mathrm{g}$ to $5.64 \mathrm{mmol} / \mathrm{g}$. The monomolecular sorption has been described from the perspective of the Langmuir theory. Gibbs free energy of sorption has been estimated. The isotherm of methanal uptake at $298 \mathrm{~K}$ in the whole range of concentra-
\end{abstract}


tion is described by BET equation. The method of IR-spectroscopy confirms chemisorption of methanal by the ion-exchanger used. of sorption.

Keywords: fibrous ion-exchange resin, methanal, sorption isotherm, uptake kinetics, limiting stage

\section{Введение}

На современном этапе развития промышленности одной из важнейших эколого-химических задач является извлечение вредных примесей из воздуха, вод различного назначения и других жидких сред [1]. Среди таких примесей весомый вклад в загрязнение окружающей среды вносят алифатические карбонильные соединения, в частности, метаналь (формальдегид). Наличие данного альдегида в воде и атмосферном воздухе крайне нежелательно, и требуется очистка содержащих его стоков и выбросов.

Снижение содержания карбонильных соединений в жидких средах может быть осуществлено различными методами, в том числе с использованием сорбционных технологий. Одной из перспективных разработок является способ извлечения альдегидов с применением в качестве сорбентов низкоосновных анионообменников в форме гранул [2-4]. Повышение эффективности работы полимеров с функциональными аминогруппами возможно не только за счет варьирования их основности, но также за счет использования сорбентов другой формы, например, ионообменных волокон, которые, согласно ряду работ [5-7], проявляют лучшие сорбционные характеристики по сравнению с гранульными материалами.

Цель настоящей работы - определение равновесных и кинетических характеристик сорбции метаналя из водных растворов волокнистым ионообменником ФИБАН A-5W, имеющим в структуре вторичные аминогруппы, участвующие в химической реакции с карбонильной группой.

\section{Эксперимент}

В качестве сорбата использован первый член гомологического ряда предельных алифатических альдегидов - метаналь. В качестве сорбента в исследовании применен волокнистый ионообменник ФИБАН A-5W («Институт физикоорганической химии Национальной академии наук Беларуси», Минск). Данный сорбент представляет собой полиакрилонитрильное волокно с функциональными вторичными и третичными аминогруппами в форме свободного основания.

Изучение кинетических особенностей поглощения альдегида проводилось на основе анализа кинетических кривых сорбции, полученных в статических условиях в термостатируемом шейкере со скоростью перемешивания 220 об/мин, с использованием метода ограниченного объема. По экспериментальным данным строились зависимости $\mathrm{F}-\tau$, где $\mathrm{F}=\mathrm{Q}_{\tau} / \mathrm{Q}_{\max }-$ степень завершенности процесса сорбции; $\mathrm{Q}_{\tau}-$ емкость сорбента в момент времени $\tau$, моль/г; $\mathrm{Q}_{\max }-$ емкость сорбента при $\mathrm{F}=1$, моль/г; $\tau-$ время, мин.

Изотермы сорбции метаналя получали методом переменных концентраций в статических условиях при температурах $298 \pm 2 К$ и $323 \pm 2 К$. Навески влажного волокна в форме свободного основания массой $0.5 \pm 0.0002$ г заливали раствором метаналя объемом $200.0 \mathrm{~cm}^{3}$ с различными концентрациями и перемешивали в термостатируемом шейкере до установления равновесия. 
Контроль концентрации метаналя проводили методом обратного йодометрического титрования [8]. По убыли содержания альдегида в исходном растворе рассчитывали емкость сорбента по формуле (1).

$$
Q=\frac{\left(C_{0}-C_{\text {равн }}\right) \cdot V}{m}
$$

где $\mathrm{C}_{0}, \mathrm{C}_{\text {равн }}-$ концентрации сорбата в исходном и равновесном растворах соответственно, моль/дм ${ }^{3} ; \mathrm{V}$ - объем раствора альдегида, дм³ $; \mathrm{m}$ - масса абсолютно сухого сорбента, г.

\section{Обсуждение результатов}

Скорость достижения равновесия в системе раствор сорбата-сорбент является одной из важнейших характеристик сорбционного процесса. В ходе проведенных исследований получены кинетические кривые сорбции метаналя ионообменником A-5W при разных температурах (рис. 1), концентрация исходного раствора составляла 0.0060 моль/дм³ .

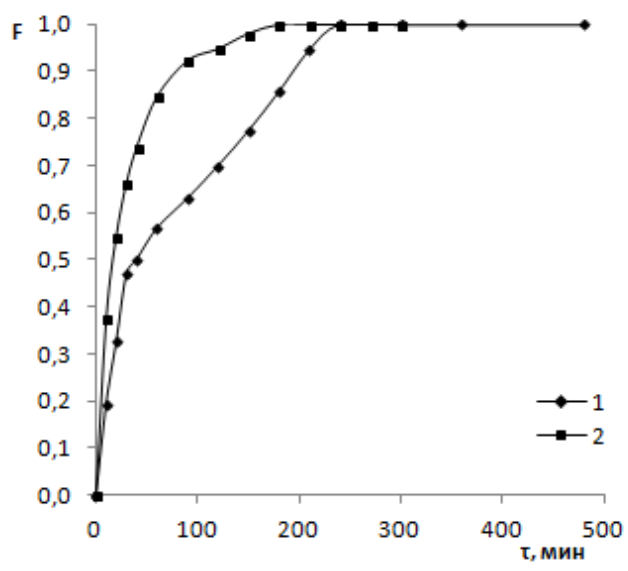

Рис. 1. Кинетические кривые сорбции метаналя ионообменником ФИБАН А-5W при температурах 298К(1) и $323 \mathrm{~K}(2)$

В работе установлено, что время достижения равновесия при сорбции метаналя из водного раствора ионообменником A-5W составляет 240 минут и 180 минут при $298 \mathrm{~K}$ и $323 \mathrm{~K}$, соответственно. При этом при температуре $298 \mathrm{~K}$ кинетическая кривая характеризуется наличием двух участков с разной скоростью сорбционного процесса, которые свидетельствуют о стадийности процесса. При более высокой температуре многоступенчатость процесса неочевидна. Возможно, полученные результаты отражают явление смены диффузионных механизмов при сорбции альдегида. На первой стадии исследуемого процесса идет сорбция за счет взаимодействия сорбата с функциональными группами на высокоразвитой поверхности волокнистого материала, вторая стадия предполагает поглощение в фазе сорбента и ограничивается внутренней диффузией метаналя. Увеличение температурного режима приводит к снижению внешнедиффузионных ограничений и скорость исследуемого процесса, лимитируется только стадией внутренней диффузии.

Для оценки влияния диффузионных процессов на скорость сорбционного взаимодействия проведен анализ кинетических кривых сорбции на основе применения формального подхода, заключающегося в линеаризации экспериментальных зависимостей в координатах уравнений Бойда-Адамсона [9] для случая внутренней (2) и внешней (3) диффузии. 


$$
\begin{array}{r}
F=1,08 \sqrt{B \tau}, \\
-\ln (1-F)=R \cdot \tau,
\end{array}
$$

где $\mathrm{F}$ - степень заполнения сорбента; В - критерий гомохромности Фурье; $\tau$ - время, $\mathrm{c} ; \mathrm{R}$ - константа скорости внешней диффузии, $\mathrm{c}^{-1}$.

Кинетические кривые сорбции метаналя ионообменником ФИБАН A-5W, представленные в координатах этих уравнений, приведены на рис. 2-3.

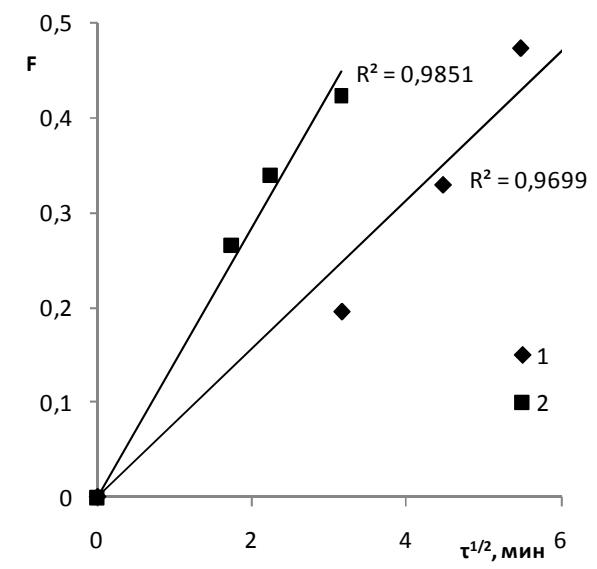

Рис. 2. Кинетические кривые сорбции метаналя ионообменником ФИБАН A-5W в координатах уравнения Бойда-Адамсона для случая внутренней диффузии при $\mathrm{F}<0.5$ :

$$
1-298 \mathrm{~K}, 2-323 \mathrm{~K}
$$

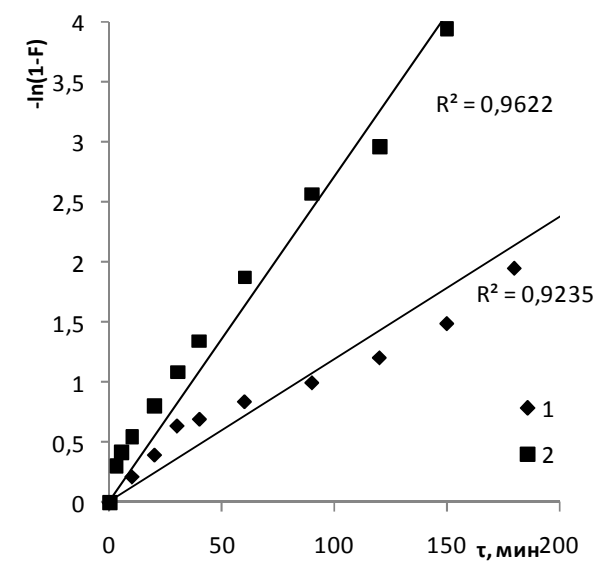

Рис. 3. Кинетические кривые сорбции метаналя ионообменником ФИБАН А-

$5 \mathrm{~W}$ в координатах уравнения Бойда-

Адамсона для случая внешней диффузии: 1 - 298K, 2 - 323K.

Установлено, что кинетические кривые сорбции метаналя исследуемым ионообменником удовлетворительно описываются уравнениями внутренней диффузии для каждой из температур, о чем свидетельствуют достаточно высокие коэффициенты корреляции. Отметим, что зависимость $-\ln (1-\mathrm{F})-\tau$ при $\mathrm{T}=298 \mathrm{~K}$ до $\tau=30$ минут показывает величину достоверности аппроксимации 0.9973 , однако далее идет перегиб на кривой и $\mathrm{R}^{2}$ во всем диапазоне $\mathrm{F}$ снижается до 0.9235. Полученный результат подтверждает предполагамое выше явление смены диффузионных механизмов сорбции метаналя.

Исходя из этого, можно сделать предположение, что сорбция метаналя A-5W при температуре 323К характеризуется внутридиффузионным механизмом, а при 298К смешаннодиффузионным.

При сравнении кинетических кривых сорбции метаналя гранульным анионообменником Purolite A 830 [10] и волокнистым сорбентом отмечается более высокая скорость на начальном участке сорбции для ФИБАН A-5W, при этом время достижения равновесия практически совпадает. Подобное явление связано с влиянием формы изготовления ионообменного материала. Волокнистые сорбенты обладают большей и более развитой поверхностью, что обеспечивает доступность большего количества функциональных групп для взаимодействия с молекулами сорбата.

Помимо кинетических характеристик сорбции метаналя волокнистым сорбентом в работе оценены равновесные характеристики при двух температурах (298K и $323 \mathrm{~K}$ ) на основе изотерм сорбции (рис. 4), полученных методом переменных концентраций. 


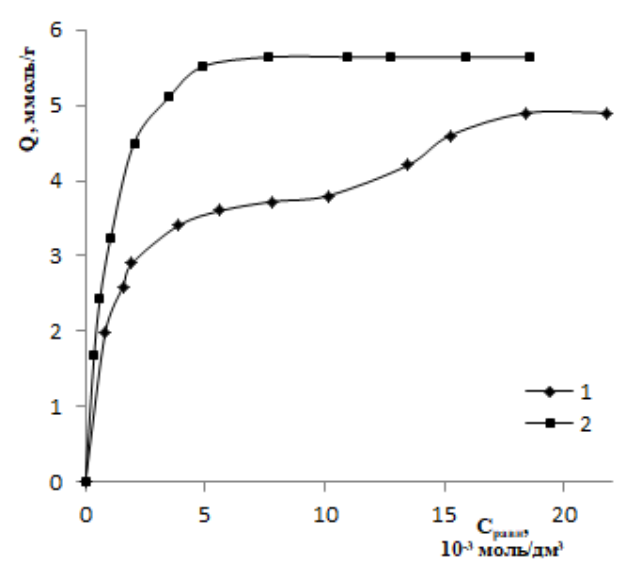

Рис. 4. Изотермы сорбции метаналя ионообменником ФИБАН А-5W при температурах 298K (1) и $323 \mathrm{~K}(2)$

По полученным кривым можно сделать вывод о том, что при температуре 298K сорбция носит полимолекулярный характер. Первый перегиб на изотерме характеризуется хемосорбционным механизмом поглощения, основанным на химической реакции между вторичными аминогруппами сорбента и карбонильной группой альдегида с образованием диалкиламинометанола [11]:

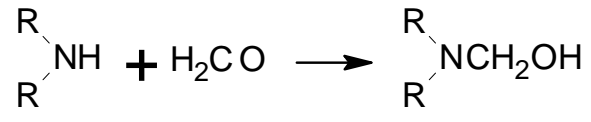

Второй перегиб на изотерме можно охарактеризовать вкладом физической адсорбции, в основе которой лежат слабые межмолекулярные силы в системе сорбат-сорбент: водородные связи и силы Ван-дер-Ваальса. При данной температуре максимальное значение емкости сорбента составляет 4.90 ммоль/г. С ростом концентрации исходного раствора альдегида в исследуемом диапазоне коэффициент распределения метаналя в системе сорбент-сорбат снижается от 2699 до 254.

При температуре $323 \mathrm{~K}$ изотерма сорбции метаналя ионообменником A-5W имеет вид выпуклой кривой с насыщением. На начальном участке при концентрации внешнего раствора менее 0.005 моль/дм ${ }^{3}$ наблюдается резкий подъем, затем происходит максимальное насыщение сорбента метаналем $\left(\mathrm{Q}_{\max }=5.64\right.$ ммоль/г) и кривая выходит на «плато». При этом значение коэффициентов распределения оказываются значительно выше, чем при 298К и изменяются от 5206 до 344 в исследуемом диапазоне концентраций. Следует отметить, что исследуемый сорбент проявляет высокое сродство к метаналю.

Для описания характера сорбции метаналя в работе использован формальный подход, основанный на применении известных теорий сорбции (Ленгмюра, Темкина, Фрейндлиха) [12-14]. Данные приведены в табл. 1.

Таблица 1. Модели сорбции, применяемые в работе

\begin{tabular}{|c|c|c|c|}
\hline \multirow{2}{*}{ Модель сорбции } & Уравнение сорбции & \multicolumn{2}{|c|}{$\mathrm{R}^{2}$} \\
\cline { 3 - 4 } Ленгмюра & $Q=Q_{\max } \cdot \frac{K \cdot C_{\text {равн }}}{1+K \cdot C_{\text {равн }}}$ & 0.999 & 0.999 \\
\hline Темкина & $F=\frac{1}{\alpha} \cdot \ln K C_{\text {равн }}$ & 0.965 & 0.953 \\
\hline Фрейндлиха & $Q=\beta \cdot C_{\text {равн }}^{1 / n}$ & 0.930 & 0.906 \\
\hline
\end{tabular}

$\mathrm{Q}_{\max }$ - максимальная емкость сорбента; $\mathrm{K}$ - константа сорбционного равновесия; $\mathrm{C}_{\text {равн }}$ - равновесная концентрация сорбата; $\alpha$ - константа, характеризующая линейное распределение сорбционных центров по энергии; $\beta$ и $\mathrm{n}-$ константы сорбции уравнения Фрейндлиха. 
Линеаризация полученных в работе изотерм (для 298К изотерма линеаризована только на начальном участке до второго перегиба) в координатах различных уравнений сорбции показывает, что наибольшие коэффициенты корреляции наблюдаются в случае представления данных в координатах уравнения Ленгмюра.

Представление изотерм сорбции метаналя ионообменником A-5W в координатах уравнения сорбции Ленгмюра позволило рассчитать кажущуюся энергию Гиббса процесса поглощения (5):

$$
\Delta G^{\prime}=-R T \ln K,
$$

где $\Delta \mathrm{G}^{\prime}$ - изменение кажущейся энергии Гиббса сорбционного процесса, кДж/моль; $\mathrm{K}$ - константа сорбционного равновесия в уравнении Ленгмюра. Значения данных характеристик сорбции представлены в табл. 2.

Также рассчитаны максимальные значения емкости сорбента, которые равны 4.14 ммоль/г для мономолекулярного слоя при $298 \mathrm{~K}$ и 5.92 ммоль/г для 323К.

Таблица 2. Характеристики сорбции метаналя ионообменником ФИБАН A-5W

\begin{tabular}{|c|c|c|}
\hline \multirow{2}{*}{ Характеристики сорбции } & \multicolumn{2}{|c|}{ Значения характеристик } \\
\cline { 2 - 3 } & $298 \mathrm{~K}$ & $323 \mathrm{~K}$ \\
\hline $\mathrm{K}$ & 1136 & 1465 \\
\hline$\Delta \mathrm{G}^{\prime}, \mathrm{\kappa Д} / \mathrm{моль}$ & -17.4 & -19.6 \\
\hline
\end{tabular}

Для описания изотермы сорбции метаналя ионообменником A-5W во всем диапазоне исследованных концентраций при $298 \mathrm{~K}$ использовано уравнение полимолекулярной сорбции Брунауэра-Эммета-Теллера (БЭТ), модифицированное для жидких сред:

$$
Q=Q_{\max } \frac{K_{S} C_{\mathrm{paвн}}}{\left(1-K_{L} C_{\mathrm{paвH}}\right)\left(1-K_{L} C_{\mathrm{paвH}}+K_{S} C_{\text {равн }}\right)},
$$

где $\mathrm{K}_{\mathrm{S}}-$ коэффициент сорбционного равновесия первого адсорбционного слоя; $\mathrm{K}_{\mathrm{L}}$ - коэффициент сорбционного равновесия для полимолекулярного слоя.

Линеаризация изотермы сорбции метаналя в координатах линейной формы уравнения (6) позволила рассчитать значение коэффициента корреляции $\mathrm{R}^{2}=0.991$. Высокое значение данного коэффициента подтверждает, что сорбция метаналя ионообменником A-5W при $298 \mathrm{~K}$ во всем диапазоне исходных концентраций может быть удовлетворительно описана моделью полимолекулярной сорбции.

Для подтверждения структурных изменений в фазе сорбента при контакте с алифатическим альдегидом получены ИК-спектры исследуемого ионообменника до и после поглощения метаналя из его водного раствора (рис. 5).

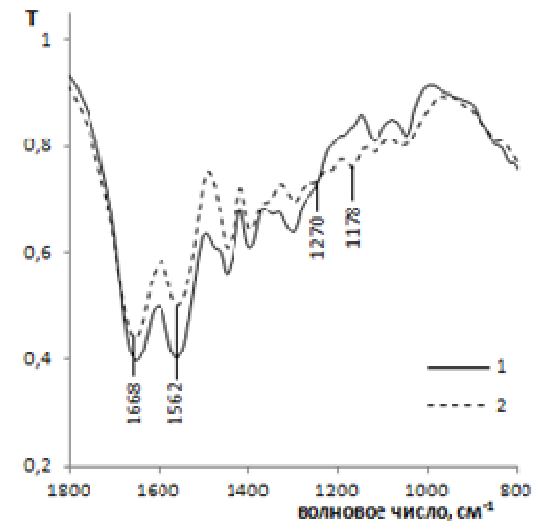

Рис. 5. ИК-спектры ионообменника ФИБАН А-5W:

1 - форма свободного основания, 2 - форма, насыщенная метаналем

Васильева и др. / Сорбционные и хроматографические процессы. 2019. Т. 19. № 2 
Полоса поглощения ИК-излучения при $1562 \mathrm{~cm}^{-1}$ характерна как для -O-H группы, так и для вторичной аминогруппы, вследствие этого уменьшение ее интенсивности косвенно свидетельствует о взаимодействии ионообменника с формальдегидом. Появление малоинтенсивного пика при $1270 \mathrm{~cm}^{-1}$, характерного для колебания $\mathrm{C}-\mathrm{O}$ - группы в спиртах, указывает на образование аминоспирта в фазе сорбента. Полоса поглощения ИК-излучения $1178 \mathrm{~cm}^{-1}$ характеризует колебания третичных аминогрупп, их количество увеличивается вследствие протекания химического взаимодействия альдегида с сорбентом по мезанизму (4).

\section{Заключение}

В работе получены кинетические кривые сорбции метаналя волокнистым ионообменником ФИБАН A-5W при разных температурах из водных растворов с концентрацией 0.0060 ммоль/дм ${ }^{3}$, которые указывают на изменение диффузионного механизма поглощения альдегида при повышении температуры. Установлено, что время достижения равновесия в системе раствор метаналя - ионообменное волокно при повышении температуры снижается с 240 минут до 180 минут. Проведенный формальный анализ полученных экспериментальных зависимостей с использованием уравнений Бойда-Адамсона позволяет сделать предположение о лимитировании скорости процесса сорбции стадией внутренней диффузии сорбата в объеме волокна сорбента при температуре 323 и и смешаннодиффузионном механизме сорбции при $298 \mathrm{~K}$.

Исследованы равновесные характеристики сорбции метаналя в системе ионообменник - раствор альдегида. Механизм поглощения с образованием мономолекулярного слоя описан с позиции теории сорбции Ленгмюра. Рассчитаны константы сорбционного равновесия, значения предельной емкости сорбента, а также энергетические характеристики процесса сорбции. Методом ИК-спектроскопии подтверждено поглощение метаналя исследуемым ионообменником с участием вторичных функциональных аминогрупп.

Благодарим зав. лабораторией синтеза и исследования свойств ионообменных волокон «Института физико-органической химии Наџиональной Академии наук Беларуси» А.П. Поликарпова за предоставленные образиы волокнистого ионообменника A-5W. ИК-спектры получены на оборудовании ЦКП НО ВГУ. Выражаем благодарность доченту А.Н. Лукину.

\section{Список литературы}

1. Платонов И.А., Арутюнов Ю.И. Хроматографический анализ примесей: учебное пособие. Самара: Универс-групп. 2006. 59 с.

2. Раков Э.М. // Журн. прикл. химии. 1973. Т. 46. № 11. С. 2449-2452.

3. Воронюк И.В. // Дис. ... канд. хим. наук. : 02.00.04: защищена 29.12.2011. Воронеж. 2011. $177 \mathrm{c}$.

4. Воронюк И.В., Елисеева Т.В. // Сорбиционные и хроматографические прочессы. 2018. T. 18. № 2. C. 231-237.

5. Петрова Е.В. // Известия Томского политех. ун-та. 2007. № 2. С. 136-140.
6. Медведева И.Б. // Атомная энергия. 2003. № 5. C. 367-373.

7. Мещерякова А.В., Воронюк И.В., Елисеева Т.В., Поликарпов А.П. и др.// Сорбичионные и хроматографические проиессы. 2016. T. 16. № 4. C. 496-504.

8. РД 52.24.492-2006. Массовая концентрация формальдегида в водах. Методика выполнения измерений фотометрическим методом с ацетилацетоном. Ростов-на-Дону. 2006. $30 \mathrm{c}$. 
9. Boyd G.E., Adamson A.W., Myers L.S. // J. Amer. Chem. Soc. 1947. Vol. 69. No 11. pp. 2836-2848.

10. Воронюк И.В, Елисеева Т.В., Черникова И.Ю., Лобова Н.А. // Сорбционные и хроматографические процессы. 2011. Т. 11. № 5. C. $679-682$.

\section{References}

1. Platonov I.A., Arutyunov Yu.I., Khromatograficheskii analiz primesei: uchebnoe posobie, Samara: Univers-grupp, 2006, 59 p.

2. Rakov E.M., Zhurn. prikl. Khimii, 1973, Vol. 46, No 11, pp. 2449-2452.

3. Voronyuk I.V., Dis. ... kand. khim. nauk.: 02.00.04: zashchishchena 29.12.2011. Voronezh, 2011, 177 p.

4. Voronyuk I.V., Eliseeva T.V., Sorbtsionnye $i$ khromatograficheskie protsessy. 2018. Vol. 18. No 2. pp. 231-237.

5. Petrova E.V., Izvestiya Tomskogo politekh. un-ta, 2007, No 2, pp. 136-140.

6. Medvedeva I.B., Atomnaya energiya, 2003, No 5, pp. 367-373.

7. Meshcheryakova A.V., Voronyuk I.V., Eliseeva T.V., Polikarpov A.P. et al., Sorbtsionnye $i$ khromatograficheskie protsessy, 2016, Vol. 16, No 4, pp. 496-504.

Васильева Екатерина Вячеславовна - студентка кафедры аналитической химии ФГБОУ ВО «Воронежский государственный университет», Воронеж

Воронюк Ираида Владимировна - к.Х.Н., доцент кафедры аналитической химии ФГБОУ ВО «Воронежский государственный университет», Воронеж

Елисеева Татьяна Викторовна - к.х.н., доцент кафедры аналитической химии ФГБОУ ВО «Воронежский государственный университет», Воронеж
11.Уокер Дж.Ф. Формальдегид; Пер. с англ. П.П. Коржева. М. : Госхимиздат. 1957. $608 \mathrm{c}$.

12.Langmuir J. // J. Am. Chem. Soc. 1916. Vol. 38. No 11. pp. 2221-2295.

13.Freundlich H.M.F. // J. Phys. Chem. 1906. Vol. A57. pp. 385-410.

14.Воюцкий С.С. Курс коллоидной химии. М. Химия. 1976. 512 с.

8. RD 52.24.492-2006. Massovaya kontsentratsiya formaldegida v vodakh. Metodika vypolneniya izmerenii fotometricheskim metodom s atsetilatsetonom. Rostov-na-Donu, 2006, 30 p.

9. Boyd G.E., Adamson A.W., Myers L.S., J. Amer. Chem. Soc., 1947, Vol. 69, No 11, pp. 2836-2848.

10. Voronyuk I.V, Eliseeva T.V., Chernikova I.Yu., Lobova N.A., Sorbtsionnye i khromatograficheskie protsessy, 2011, Vol. 11, No 5, pp. 679-682.

11. Walker J.F., Formaldehyde, New York, 1964, $408 \mathrm{p}$.

12. Langmuir J., J. Am. Chem. Soc., 1916, Vol. 38, No 11, pp. 2221-2295.

13. Freundlich H.M.F., J. Phys. Chem., 1906, Vol. A57, pp. 385-410.

14. Voyutskii S.S. Kurs kolloidnoi khimii, M., Khimiya, 1976, 512 p.

Vasileva Ekaterina V. - student, Department of Analytical Chemistry, Voronezh State University, Voronezh, e-mail: vasilevakatya1995@mail.ru

Voronyuk Iraida V. - assistant professor, Department of Analytical Chemistry, Voronezh State University, Voronezh, e-mail: i.voronyuk@yandex.ru

Eliseeva Tatiana V. - assistant professor, Department of Analytical Chemistry, Voronezh State University, Voronezh, email:tatyanaeliseeva@yandex.ru 